\title{
A Novel Technique of Full-Thickness Scleral Debridement in Fulminant Necrotising Infectious Scleritis and Its Outcomes - A Consecutive Case Series
}

SAMENDRA KARKHUR ( $\sim$ karkhurs@gmail.com)

All India Institute of Medical Science - Bhopal https://orcid.org/0000-0002-6991-4746

DEEPAK SONI

All India Institute of Medical Science - Bhopal

BHAVANA SHARMA

All India Institute of Medical Science - Bhopal

\section{Research Article}

Keywords: Infectious scleritis, scleral debridement, ciliary staphyloma, scleral abscess, ocular trauma

Posted Date: March 16th, 2021

DOI: https://doi.org/10.21203/rs.3.rs-307138/v1

License: () (i) This work is licensed under a Creative Commons Attribution 4.0 International License. Read Full License

Version of Record: A version of this preprint was published at International Ophthalmology on October 6th, 2021. See the published version at https://doi.org/10.1007/s10792-021-02030-6. 


\section{Abstract}

Purpose

We report the outcomes of a novel technique of scleral debridement in five consecutive cases of relentlessly progressive and fulminant infectious scleritis following corticosteroid exposure.

Methods

Five consecutive patients of infectious scleritis with a common history of corticosteroids exposure; resulting from either an initial misdiagnosis of autoimmune scleritis or as an adjunct to specific antimicrobial therapy. Data collection included presentation details including photographs, clinical findings, microbiological analysis, treatment details and audit of surgical videos. Cases with undisputed diagnosis of infectious scleritis with microbiological evidence; without corticosteroid use, were excluded from study.

Results

After full-thickness scleral debridement and cessation of corticosteroids, favourable anatomical and visual outcome was observed in all cases; however, two patients required multiple scleral debridements due to progressive scleritis. Scleral patch graft was not used in any case. Microbiology detected infective organisms in two cases, while the remaining revealed negative results. Therefore, specific antimicrobial therapy was initiated in former, whereas empirical broad-spectrum regimen in patients with repeatedly negative results. No recurrence of scleritis or development of ciliary staphyloma was noted and anatomical integrity was maintained at normal intraocular pressure during follow-up.

Conclusion

This study highlights the fulminant and relentlessly progressive clinical course, that infectious scleritis can metamorphose into, despite specific anti-microbial therapy, if inadvertent corticosteroid therapy is administered. Full-thickness debridement without scleral patch graft could achieve elimination of infectious foci with favourable long-term anatomical and visual outcome. This technique could offer a potential last resort approach in such cases where standard therapeutic modalities have not been successful.

\section{Introduction}

Scleritis is an uncommon, painful and sight threatening ocular inflammatory condition with a prevalence of 6 cases per 100,000 [1,2]. Scleritis is more commonly associated with autoimmune disorders and infectious scleritis accounts for only $5-10 \%$ of all the scleritis cases [3-6]. The initial presentation of infectious scleritis can mimic its immune mediated counterpart $[7,8]$. Topical and systemic steroids, whilst beneficial in immune mediated scleritis, worsen infectious scleritis. The latter may occur post- trauma, ocular surgery, endophthalmitis or from a primary corneal infection [9]. The most common organisms responsible for infectious scleritis are Pseudomonas aeruginosa and fungi $[7,10,11]$.

Infectious scleritis follows an aggressive course and the clinical outcome is poor in most cases with various series reporting the need for evisceration in severe cases $[9,12]$. Early initiation of topical and systemic antimicrobial therapy along with surgical debridement can help in salvaging these eyes with improved anatomical success $[7,11]$. Surgical debridement also aids in the penetration of topical medications while debulking the infected scleral tissue [8].

In this study, we report five consecutive cases of infectious scleritis with relentless progression despite medical management and focal debridement. These cases were successfully managed by full-thickness, and when required - circumferential, scleral debridement procedure.

\section{Materials And Methods}

Five consecutive patients of infectious scleritis were analysed in a retrospective review conducted at a tertiary eye hospital in central India during one-year period in 2019. Diagnosis was based on proven microbiology and/or worsened clinical course following corticosteroid administration. There was a common history of corticosteroid use, resulting from either an initial misdiagnosis of autoimmune scleritis or as an adjunct to specific antimicrobial therapy. Initial misdiagnoses were attributed to either an overlap of clinical characteristics between infectious and autoimmune scleritis, with an unclear history of trauma or a negative microbiological yield. All cases had a documented worsening of clinical picture after corticosteroid therapy and were managed by full thickness scleral debridement at our institute. This was carried out only as a last-resort procedure where the disease was relentlessly progressive despite focal debridement procedures and culture specific antimicrobial therapy. Patient's referral notes were reviewed for details of medical therapy, microbiological evidence or any previous surgical procedure. The study adheres to tenets of the Declaration of Helsinki. Written informed consent was obtained from all patients for the surgical procedure and potential complications and outcome. Consent was also obtained for use of clinical data 'without identifiers' for potential future academic use or research publications.

\section{Data analysis}

Clinical records of five patients with infectious scleritis who underwent full-thickness scleral debridement were retrospectively reviewed. Data collection included details of clinical picture at presentation including photographs, best corrected visual acuity (BCVA), intraocular pressure (IOP), detailed ocular examination including fundus, anterior segment photos and audit of surgical videos. Debrided scleral tissue was subjected to microbiological analysis and histopathological examination (HPE). Microbiological assessment included; Grams stain, $\mathrm{KOH} /$ Calcofluor-white stain and Ziehl-neelsen staining. Acid-fast staining was done if grams stain was negative, and the clinical picture strongly suggested of microbial/infective origin. The samples from scleral scraping were cultured on blood agar, chocolate agar, Sabouraud's dextrose agar and non-nutrient agar with an E. coli overlay. Details of the type of antimicrobial

Page 2/10 
agents and their doses were noted. Treatment and surgical procedure details of patients referred from elsewhere were also recorded. All patients included in the study had a documented follow up period of at least one year.

\section{Technique of Scleral Debridement}

All procedures were performed under local peribulbar anaesthesia. After standard preparation of the surgical field with $5 \%$ povidone iodine and draping, a lid speculum was placed. Conjunctiva was opened using scissors, initially at the location of the most prominent, yellowish nodular elevation which often led to the drainage of frank pus and subsidence of swelling; thus, confirming the presence of a sub-conjunctival abscess. Using a surgical blade (15 no.) mounted on Bard-Parker handle, necrotic sclera was debrided until the underlying healthy scleral tissue was visible and fresh bleeding was encountered. In a few areas upon excision of overlying conjunctiva, bare choroid was exposed; this was suggestive of full thickness scleral necrosis.

In cases with a more aggressive clinical picture, full-thickness scleral necrosis was noticed (360 degrees) and necrotic sclera was excised using conjunctival scissors, advancing in a circumferential fashion. In order to achieve this, one blade of the conjunctival scissors was slipped gently between the cheesy necrotic sclera and choroid - directly placing it in the suprachoroidal space. After excising the necrotic melted scleral tissue off the underlying uveal tissue, an annular band of deeply pigmented, bare-choroid was visible; anteriorly limited to perilimbal $5 \mathrm{~mm}$ - zone of scleral frill and posteriorly till the insertion of rectus muscles (along the spiral of Tillaux). No event of globe rupture with vitreous loss or choroidal hemorrhage was encountered in any of the cases. Primary closure was not performed and the conjunctiva overlying the area of scleral necrosis was excised in order to ensure better penetration of medications, prevent re-organization of abscess and to maximise elimination of infection. Before patching, the wound and debrided area were thoroughly irrigated using broad spectrum antibiotic solution.

\section{Results}

Of the five patients enrolled in the study two were females. Three patients presented with scleritis which was initially misdiagnosed as autoimmune and started on corticosteroids. However, when the clinical picture worsened into fulminant necrotising full-thickness scleritis with relentless progression despite initial management, the diagnosis was revised to consider infectious etiology and corticosteroids stopped henceforth. Remaining two patients had a microbiologically proven etiology of infectious scleritis, but were given steroids as an adjunct, to control scleral inflammation under cover of specific antimicrobial therapy. Corticosteroids in these cases were started after clinical resolution was documented and a minimum intervening period of one-week between both therapies. The individual case details, clinical course, management and outcomes have been described below.

\section{Case 1}

A 55-year-old male presented with complaints of redness and pain in the left eye for two months. (Fig 1a) BCVA was 20/100 in left eye (OS). Patient had undergone focal superficial debridement outside, one-month prior to presentation. Specimens sent for microbiological analysis had not yielded any positive results. Patient was being treated with high-dose systemic steroids along with empirical broad-spectrum antimicrobial therapy. Systemic history and examination were not contributory with no history of any risk factors like previous surgery and trauma. However, he had continued to worsen with severe pain and was referred to our centre. On examination, diffuse conjunctival congestion with multiple scleral abscesses were noted, and the site of earlier debridement revealed an adjacent pus-point. Smear and culture reports from abscess were inconclusive. Serum rheumatoid arthritis (RA) factor, anti-nuclear antibody (ANA), cytoplasmic and peri-nuclear anti-neutrophil cytoplasmic antibodies (c-ANCA, and p-ANCA) were negative. Based on worsening clinical course while on corticosteroid therapy and multiple scleral abscesses; a diagnosis of infectious scleritis was made despite negative microbiological testing and a 360-degree scleral debridement was performed. (Fig 1b) All forms of steroids were immediately stopped, and the patient was started empirically on intravenous thirdgeneration cephalosporin (cefotaxime 1g every 8 hours) with fortified topical vancomycin (5\%) and tobramycin (1.4\%) every 2 hours. Anti-glaucoma medication were added to the regimen. At one-week follow up, patient had become pain-free and the eye was less congested with minimal discharge. At onemonth, complete epithelialization of bare-choroid was visible without any staphylomatous bulge. (Fig 1c-d) Intraocular pressure was normal with a formed anterior chamber. Systemic antibiotics and anti-glaucoma therapy were withdrawn at the end of one-month.

\section{Case 2}

A 60-year-old male presented with complaints of pain, redness and discharge in the left eye for 15 days. BCVA was finger counting close to face. Patient had undergone an uneventful manual - small incision cataract surgery, two-months prior to presentation. The patient was stable post-operatively. Examination revealed focal necrotising scleritis at the incision site, hypopyon and dense vitritis. A diagnosis of post-surgical infectious scleritis with endophthalmitis was made. Topical moxifloxacin $0.5 \%$ and intravitreal antibiotics (vancomycin $1 \mathrm{mg} / 0.1 \mathrm{ml} \&$ ceftazidime $2.25 \mathrm{mg} / 0.1 \mathrm{ml}$ ) were administered and vitreous tap was subjected to microbiological analysis; which did not reveal any organisms. Topical therapy was continued, and oral steroids were also initiated as per standard regimen (tablet prednisolone $0.5 \mathrm{mg} / \mathrm{kg}$ once a day) for endophthalmitis along with oral antibiotics (tablet ciprofloxacin $500 \mathrm{mg}$ two times a day). Next follow up review after one-week revealed a superior perilimbal uveal show with surrounding necrotic scleral tissue, congestion, increased pain and discharge. Several new lesions of active scleritis had also developed with multifocal abscesses. Gram stain and culture results of focal superficial debridement revealed Pseudomonas aeruginosa. In view of culture results and progressive necrotising scleritis - fortified topical tobramycin (1.4\%) was added, Systemic antimicrobials based on sensitivity (similar to Patient 1) were initiated, and corticosteroids were withdrawn. Despite treatment revision, the lesions continued to progress; hence full-thickness circumferential scleral debridement was performed to save the eye and prevent evisceration. (Fig $2 \mathrm{a}$ ) Progressive clinical improvement was noted post-operatively and on subsequent follow up visits. At one-year follow up, the patient had a BCVA of 20/160, all medications were stopped and had a normal IOP with posterior capsular opacification; without any recurrence or evidence of ciliary staphyloma. (Fig $\mathbf{2 b}$ )

Case 3 
A 44-year-old female presented with complaints of redness, pain and swelling in her left eye for two weeks. (Fig 3a) There was an unclear history of trauma by vegetative matter two weeks prior to presentation. Examination revealed a BCVA of 20/80. No signs of trauma or foreign body was found and a provisional diagnosis of autoimmune diffuse anterior scleritis was made and the patient was initiated on topical corticosteroids with oral indomethacin. Due to inadequate improvement in clinical picture, the patient was started on oral corticosteroids on subsequent visits, followed by a transient improvement in signs and symptoms. The systemic vasculitis/rheumatologic workup was negative and hence the patient was continued on systemic corticosteroids. At two weeks follow-up, the clinical picture had rapidly deteriorated, and examination revealed a well-defined, boggy swelling at the site of initial congestion with worsened pain. An abscess was suspected, and the patient was taken up for exploration. Bare choroid with full thickness scleral melt was noted on conjunctival incision. (Fig 3b) Microscopy revealed septate fungal hyphae and culture report showed Fusarium spp. Oral steroids were urgently withdrawn while the patient was started on oral and topical antifungal treatment (topical voriconazole $1 \%$ every 2 hours and oral voriconazole 200 mg two times day). Following specific antifungal therapy, lesions showed significant resolution; therefore, corticosteroid adjunctive therapy was also added to this regimen to prevent collateral damage due to persistent scleral inflammation However, two weeks later patient returned with new lesions - identified as multifocal scleral abscesses. (Fig 3c) Multiple scleral debridement procedures were undertaken, since the lesions continued to progress in an annular fashion, until total 360-degree band of scleral tissue was excised. Anti-fungal therapy could be withdrawn at the end of three months. At one-year follow-up, patient had BCVA of 20/30. The integrity of the globe was maintained with a normal IOP and no signs of recurrence or ciliary staphyloma. A distinct deep blue to black, circumferential band of uveal tissue (approximately $6-8 \mathrm{~mm}$ in width) is noticed with healthy epithelization and vascularization. (Fig $\mathbf{3 d}$ )

\section{Case 4}

A 50-year-old female presented with complaints of redness and pain in her left eye for five days. Examination revealed a BCVA of 20/40, circumcorneal congestion, anterior chamber cells and normal posterior segment. (Fig 4a) Patient was prescribed topical corticosteroids (prednisolone acetate $1 \%$ every two hours) and cycloplegics (atropine sulphate $1 \%$ three times a day) and was asked to return after one week. A week later, vision had dropped to $20 / 500$ with fibrin in the anterior chamber and no view of the fundus, ultrasonography (USG B-scan) revealed normal posterior segment study. Rheumatology work up and serology testing were inconclusive with regard to associated systemic vasculitits. Provisional diagnosis of acute-fibrinous anterior uveitis with diffuse-anterior scleritis was made and systemic corticosteroids (tablet prednisolone $1 \mathrm{mg} / \mathrm{kg}$ once a day) were initiated in addition to topical therapy. There was progressive deterioration of clinical picture on further follow up, while still being on adequate corticosteroid therapy. On review and reassessment, the possibility of an infectious etiology was considered, which was further corroborated by the development of a scleral abscess. Although, smear and culture results were negative, yet all forms of corticosteroids were withdrawn, and empirical antimicrobials were initiated. Due to continued annular progression of necrotising scleritis and appearance of multifocal abscesses, with inconclusive microbiology results the patient was taken up for circumferential scleral debridement. (Fig 4b) Broad-spectrum antimicrobials (similar to Patient 1) were continued. Patient was symptomatically better during subsequent visits. (Fig 4c) Eight months following full-thickness surgical debridement, the patient underwent an uneventful phacoemulsification with IOL implantation. The phacodynamics were titrated to low-flow/vacuum settings and chamber stability was ensured with appropriate interventions throughout surgery. At one-year of follow up, patient achieved a BCVA of 20/80 with a quiet eye, normal fundus, and no signs of recurrence or ciliary staphyloma. Anatomical integrity of the globe was preserved, and intraocular pressure was $16 \mathrm{~mm} \mathrm{Hg}$. (Fig 4d)

\section{Case 5}

A 50-year-old male presented with complaint of pain in the left eye for 15 days. He was initially diagnosed as having nodular episcleritis based on presenting clinical picture and was treated with topical steroids (prednisolone acetate $1 \%$ every two hours) and cycloplegics (atropine sulphate $1 \%$ three times a day). His presenting BCVA was 20/40. On subsequent follow-ups his condition worsened, thus systemic corticosteroids (tablet prednisolone $1 \mathrm{mg} / \mathrm{kg}$ once a day) were added to the regimen (Fig 5a), despite which the condition continued to worsen and developed a violaceous raised lesion with tortuous conjunctival vessels, appearing in the perilimbal area. The patient was taken up for scleral debridement. A $180^{\circ}$ temporal full-thickness scleral debridement was performed in view of total scleral-melt in the affected area. (Fig 5b) Further progression necessitated additional debridement of the upper-nasal sclera. Gram staining revealed the presence of neutrophils with no detectable organisms. Broad-spectrum antibiotics were empirically added (similar to Patient 1). One-week post debridement, the patient improved symptomatically. (Fig 5c) A month after the debridement, the patient had a BCVA of 20/100 with minimal discharge and conjunctival congestion. Topical antibiotics and anti-glaucoma medications were continued. Three months after debridement, the patient was maintaining a BCVA of 20/80 with uveal show, no evidence of congestion and an IOP of $10 \mathrm{~mm} \mathrm{Hg}$. (Fig 5d)

In three out of the five cases (case 1, 4 \& 5), microbiology was inconclusive. (Table 1) No microorganisms/fungal hyphae were observed on HPE of the debrided scleral tissue, however all cases revealed features suggestive of necrotising inflammation. Case 1 was suspected to be infectious scleritis based on clinical picture, however due to lack of microbiological evidence the autoimmune etiology was considered and corticosteroids were started. In contrast to Case 1 - Case 4 \& 5 were initially misdiagnosed as autoimmune scleritis based on mimicking clinical presentation and negative microbiological yield but progressive worsening on corticosteroid therapy confirmed otherwise. In case $2 \& 3$ corticosteroids were started as adjunct to specific anti-microbial therapy and still caused unabated progression of disease. All patients improved after debridement and had a stable course without recurrence at one-year follow up. Anti-glaucoma therapy was given in all cases to achieve target IOP of $10-12 \mathrm{~mm}$ of $\mathrm{Hg}$; in view of lack of scleral support during the initial one-month postoperatively. We observed that patients worsened on corticosteroids therapy to acquire a relentless clinical course; despite being on a microbiologically proven etiology and concurrent specific/culture-sensitive antimicrobial therapy (Case $2 \& 3$ ). This aggressive clinical metamorphosis led to full-thickness necrotising scleritis and could eventually, only be managed by full-thickness debridement.

\section{Discussion}

Scleritis is more commonly associated with autoimmune disorders than with infectious etiologies [13]. Owing to the overlap of presenting clinical features, infectious scleritis is often initially misdiagnosed and treated with corticosteroids, leading to worsening of the disease into a fulminant and relentlessly 
progressive clinical course. Aggressive surgical management may often be required for globe salvage in these cases. Pseudomonas, Staphylococcus, and Herpes zoster are common agents that can cause infectious scleritis which mimics autoimmune disease $[8,14]$.

All five patients in our study had a common history of treatment with systemic steroids that may have led to worsening of their scleritis. (Table 1 ) Sahu et al observed that in their cohort of 17 patients with infectious scleritis, 15 were on topical steroids. The authors have attributed the worsening of infections in these patients to the inhibition of lysosomal enzymes and suppression of immunity [15].

Patient 1 presented to us after focal debridement and abscess drainage carried out at another facility and was treated with systemic steroids throughout because the microbiology was non-revealing. In view of the fulminant clinical picture, the patient was promptly taken up for surgical debridement. Tittler et al reported improved functional outcomes of patients with infectious scleritis who were treated with prompt and aggressive scleral debridement and antimicrobial therapy; the authors observed that a delayed debridement was associated with poorer outcomes [16].

Patient 2 presented two months after cataract surgery with a surgical wound infection. Infectious scleritis has been reported after various surgical procedures like pterygium excision, cataract and vitreoretinal surgery $[11,17,18]$. Patients with a prior history of ocular surgery and then presenting with necrotising scleritis at the site of tissue penetration should be suspected to have infectious scleritis. The presentation at two months is similar to that observed by Hodson et al; who noted that fastidious organisms had a longer time between symptoms and diagnosis than the non-fastidious ones [17].

Patient 3 gave a history of trauma by vegetative matter. Reddy et al noted a history of trauma in $22 \%$ of scleritis due to infectious etiology [19]. Ahn et al observed a poorer prognosis amongst eyes with fungal scleritis, most likely due to delay in diagnosis and its rapid worsening with steroids [20]. Jain et al observed that fungal scleritis was more commonly seen in areas of hot, humid climate and found Aspergillus and Nocardia to be the most common pathological agents. Of the eight cases of fungal scleritis, four eyes were eviscerated and only one retained useful vision despite adequate antifungal therapy and surgical debridement in their series. This highlights the need for prompt diagnosis and early, aggressive surgical debridement [7]. Multiple scleral debridements were performed in our cases, which are frequently needed in fungal scleritis due to the increased incidence of recurrence as reported by Reddy et al [19].

Patient 4 initially presented with a clinical picture of acute anterior uveitis with diffuse-anterior scleritis, which worsened on corticosteroids and led to formation of scleral abscess. These abscesses are most commonly located along an arc 3-4 mm from the limbus as observed by Hsiao et al [11]. The patient underwent an uneventful phacoemulsification and had a stable postoperative course, revealing the stability of the globe post-circumferential debridement

Patient 5 presented with a condition mimicking nodular episcleritis. This case also highlighted the fact that infectious scleritis may be confused initially with its autoimmune counterpart and the administration of corticosteroids may be considered in a step-wise fashion. However, once the misdiagnosed infectious etiology was exposed to systemic steroids, the progression was unabated, only to culminate in a full-thickness necrotising involvement of scleral tissue - thus mandating an aggressive surgical approach.

Surgical debridement plays an important role in the management of infectious scleritis. The relative avascularity of the sclera and the dense structure of the collagen fibers hinder penetration by topical and systemic antibiotics [20]. The picture is further complicated in infectious scleritis of fungal etiology where hyphae are enmeshed into scleral lamellae extending into the apparently uninvolved tissue. Hence surgical debridement needs to be aggressive and extensive without sparing the overlying conjunctiva. Also, debridement provides samples for microbiological analysis, further aiding establishment of definitive diagnosis and early institution of targeted therapy.

Conjunctival excision is recommended in order to prevent re-organization of abscess after surgical debridement, enhance drug-penetration and maximise elimination of infection. Tittler et a/ demonstrated a $100 \%$ globe preservation rate, improved visual rehabilitation and fewer complications by doing a prompt surgical debridement at diagnosis [16]. We performed a full thickness surgical debridement in all cases, since it has been reported that aggressive early debridement not only debulks the infected scleral tissue, but also aids in antibiotic penetration $[15,19]$.

It must however be remembered that one needs to exercise extreme caution while performing full-thickness excision of necrosed and melted scleral tissue (often with circumferential extent and cheesy consistency in steroid exposed cases) as discussed in our study. One blade of the scissors is circumferentially slid into the supra-choroidal space as far as no resistance is encountered and the affected tissue is then cut along the junction of infected and normal sclera both anteriorly and posteriorly. It has also been shown that the extent of involved sclera is better delineated intraoperatively than on clinical examination, and often the actual extent is greater, than that observed on clinical examination.

Extensive scleral debridement has also been shown to require patch-graft [7,15]. However, in our series, scleral patch graft was not resorted to; despite extensive full-thickness debridement. In our experience, application of preserved/cadaveric, avascular, scleral patch-graft at the site of active infection not only leads to persistence of infectious focus and re-organization of abscess but also necrosis of the graft. Epithelisation of the bare choroid/uveal tissue in early post-operative period was observed.

All patients were maintained on anti-glaucoma medications for an initial one month, in order to prevent spikes in intraocular pressure due to inflammation. This was necessary to prevent the dehiscence of bare-choroid in early post-operative period; and formation of ciliary staphyloma in late post-operative period - which may occur due to circumferential lack of scleral support.

Recurrences in case of infectious scleritis are rare after complete resolution as opposed to autoimmune scleritis, where frequent recurrences occur [17]. We observed similar findings in our series where none of the patients had recurrence after scleral debridement until a follow up period of one year. The integrity of the globe was maintained as demonstrated by an uneventful phacoemulsification with intraocular lens implantation in one patient and stable postoperative course in all patients. Thus, good anatomical and visual outcome after the procedure was achieved without the use of a scleral patch graft in any case.

Page 5/10 
To conclude, infectious scleritis should be considered in patients showing inadequate clinical response to steroid therapy, reactivation/non-resolution of an existing lesion or appearance of new lesion/lesions. History of trauma may not be forthcoming in all cases especially when a trivial trauma has gone unnoticed. Full-thickness removal of infected and necrosed sclera appears to be a safe procedure in managing such cases of infectious scleritis especially following steroid exposure. This study highlights the fulminant and relentlessly progressive clinical course, that infectious scleritis can metamorphose into, despite specific anti-microbial therapy, if inadvertent corticosteroid therapy has been administered. Full-thickness debridement without scleral patch-graft could achieve elimination of infectious foci with favourable long-term anatomical and visual outcome. This technique could offer a potential last resort approach in such cases where standard therapeutic modalities have not been successful.

\section{Declarations}

Details of one of the patients (case 3), a part of this manuscript, has been published previously by the authors in 'BMJ Case Reports'. This case series is an expansion of the previous work with the inclusion of other patients over a period of time.

- Competing Interests: All authors certify that they have no affiliations with or involvement in any organization or entity with any financial interest (such as honoraria; educational grants; participation in speakers' bureaus; membership, employment, consultancies, stock ownership, or other equity interest; and expert testimony or patent-licensing arrangements), or non-financial interest (such as personal or professional relationships, affiliations, knowledge or beliefs) in the subject matter or materials discussed in this manuscript.

\section{- Funding Info: None}

- Author contribution: SK worked up and clinically managed the cases. SK and DS performed literature review and drafted the manuscript. BS critically reviewed the manuscript.

- Data Availability: Not applicable

- Animal Research (Ethics): Not applicable

- Consent to Participate (Ethics): Informed consent was obtained from all the patients included in the study.

- Consent to Publish (Ethics): Informed consent was obtained from all the patients included in the study.

\section{References}

1. Artifoni M, Rothschild PR, Brézin A, Guillevin L, Puéchal X (2014 Feb) Ocular inflammatory diseases associated with rheumatoid arthritis. Nat Rev Rheumatol 10(2):108-116

2. Beardsley RM, Suhler EB, Rosenbaum JT, Lin P (2013) Pharmacotherapy of scleritis: current paradigms and future directions. Expert opinion on pharmacotherapy. Mar 1;14(4):411 - 24

3. Jabs DA, Mudun A, Dunn JP, Marsh MJ (2000) Episcleritis and scleritis: clinical features and treatment results. American journal of ophthalmology. Oct 1;130(4):469 - 76

4. de la Maza MS, Jabbur NS, Foster CS (1994) Severity of scleritis and episcleritis. Ophthalmology. Feb 1;101(2):389 - 96

5. Akpek EK, Thorne JE, Qazi FA, Do DV, Jabs DA (2004) Evaluation of patients with scleritis for systemic disease. Ophthalmology. Mar 1;111(3):501-6

6. Albini TA, Rao NA, Smith RE. The diagnosis and management of anterior scleritis. International ophthalmology clinics. 2005 Apr 1;45(2):191-204

7. Jain V, Garg P, Sharma S (2009 Feb) Microbial scleritis-experience from a developing country. Eye 23(2):255-261

8. Murthy SI, Sabhapandit S, Balamurugan S, Subramaniam P, Sainz-de-la-Maza M, Agarwal M, Parvesio C. Scleritis: Differentiating infectious from noninfectious entities. Indian Journal of Ophthalmology (2020) Sep 1;68(9):1818

9. Reynolds MG, Alfonso E. Treatment of infectious scleritis and keratoscleritis. American journal of ophthalmology. 1991 Nov 1;112(5):543-7

10. Huang FC, Huang SP, Tseng SH (2000 Jan) Management of infectious scleritis after pterygium excision. Cornea 19(1)(1):34-39

11. Hsiao CH, Chen JJ, Huang SC, Ma HK, Chen PY, Tsai RJ. Intrascleral dissemination of infectious scleritis following pterygium excision. British journal of Ophthalmology. 1998 Jan 1;82(1):29-34

12. Sainz de la Maza M, Hemady RK, Foster CS (1993) Infectious scleritis: report of four cases. Doc Ophthalmol 83:33-41

13. De La Maza MS, Hemady RK, Foster CS (1993 Mar) Infectious scleritis: report of four cases. Documenta ophthalmologica 83(1)(1):33-41

14. Okhravi N, Odufuwa B, McCluskey P, Lightman S. Scleritis. Survey of ophthalmology. 2005 Jul 1;50(4):351-63

15. Kumar Sahu S, Das S, Sharma S, Sahu K (2012) Clinico-microbiological profile and treatment outcome of infectious scleritis: experience from a tertiary eye care center of India. Int J Inflam 2012:753560

16. Tittler EH, Nguyen P, Rue KS, Vasconcelos-Santos DV, Song JC, Irvine JA, Smith RE, Rao NA, Yiu SC (2012) Early surgical debridement in the management of infectious scleritis after pterygium excision. Journal of ophthalmic inflammation and infection. Jun 1;2(2):81- 7

17. Hodson KL, Galor A, Karp CL, Davis JL, Albini TA, Perez VL, Miller D, Forster RK (2013) Epidemiology and visual outcomes in patients with infectious scleritis. Cornea. Apr 1;32(4):466 - 72

18. Rich RM, Smiddy WE, Davis JL. Infectious scleritis after retinal surgery. American journal of ophthalmology. 2008 Apr 1;145(4):695-9

19. Reddy JC, Murthy SI, Reddy AK, Garg P (2015 Apr) Risk factors and clinical outcomes of bacterial and fungal scleritis at a tertiary eye care hospital. Middle East African journal of ophthalmology 22(2):203

20. Meallet MA (2006) Subpalpebral lavage antibiotic treatment for severe infectious scleritis and keratitis. Cornea. Feb 1;25(2):159-63 
Tables

Table 1

Overview of the key points, presentation and management

\begin{tabular}{|c|c|c|c|c|c|c|c|c|c|}
\hline $\begin{array}{l}\mathrm{Sr} \\
\text { No }\end{array}$ & $\begin{array}{l}\text { Age } \\
\text { (years) } \\
\text { / } \\
\text { Gender }\end{array}$ & Eye & $\begin{array}{l}\text { Presenting } \\
\text { Diagnosis of } \\
\text { Scleritis }\end{array}$ & $\begin{array}{l}\text { Exposure to } \\
\text { corticosteroid \& type }\end{array}$ & Microbiology & $\begin{array}{l}\text { Extent of full- } \\
\text { thickness } \\
\text { debridement at } \\
\text { our centre }\end{array}$ & $\begin{array}{l}\text { Culture of } \\
\text { scleral } \\
\text { scrapings }\end{array}$ & $\begin{array}{l}\text { Antimicrobial } \\
\text { treatment }\end{array}$ & $\begin{array}{l}\text { Histopathology } \\
\text { of scleral } \\
\text { tissue }\end{array}$ \\
\hline 1 & $55 / M$ & Left & $\begin{array}{l}\text { Anterior } \\
\text { necrotising } \\
\text { scleritis }\end{array}$ & $\begin{array}{l}\text { Yes/ High dose } \\
\text { systemic } \\
\text { (intravenous } \\
\text { methylprednisolone) }\end{array}$ & No growth & Circumferential & No growth & $\begin{array}{l}\text { Intravenous } \\
\text { third } \\
\text { generation } \\
\text { cephalosporin } \\
\text { with fortified } \\
\text { topical } \\
\text { vancomycin } \\
\text { and } \\
\text { tobramycin }\end{array}$ & $\begin{array}{l}\text { Acute/ chronic } \\
\text { necrotising } \\
\text { scleritis }\end{array}$ \\
\hline 2 & $60 / M$ & Left & $\begin{array}{l}\text { Post cataract } \\
\text { surgery } \\
\text { endophthamitis } \\
\text { with diffuse } \\
\text { anterior } \\
\text { necrotising } \\
\text { scleritis } \\
\text { involving } \\
\text { surgical wound }\end{array}$ & $\begin{array}{l}\text { Yes/ Oral } \\
\text { (Prednisolone) }\end{array}$ & Positive & Circumferential & $\begin{array}{l}\text { Pseudomonas } \\
\text { aeruginosa }\end{array}$ & $\begin{array}{l}\text { Intravenous } \\
\text { third } \\
\text { generation } \\
\text { cephalosporin } \\
\text { with topical } \\
\text { moxifloxacin } \\
\text { and fortified } \\
\text { tobramycin }\end{array}$ & $\begin{array}{l}\text { Necrotizing } \\
\text { inflammation } \\
\text { with } \\
\text { micro } \\
\text { abscesses }\end{array}$ \\
\hline 3 & $44 / F$ & Left & $\begin{array}{l}\text { Nodular } \\
\text { anterior } \\
\text { scleritis }\end{array}$ & $\begin{array}{l}\text { Yes/ Topical and } \\
\text { oral (Prednisolone } \\
1 \% \text { and } 1 \mathrm{mg} / \mathrm{kg} \text { ) }\end{array}$ & $\begin{array}{l}\text { Fungal } \\
\text { hyphae }\end{array}$ & $\begin{array}{l}\text { Circumferential } \\
\text { (multiple } \\
\text { settings) }\end{array}$ & Fusarium spp. & $\begin{array}{l}\text { Oral and } \\
\text { topical } \\
\text { voriconazole }\end{array}$ & $\begin{array}{l}\text { Extensive } \\
\text { scleral } \\
\text { necrosis with } \\
\text { mixtures of } \\
\text { lymphocytes } \\
\text { and } \\
\text { neutrophils } \\
\text { and multifocal } \\
\text { abscesses }\end{array}$ \\
\hline 4 & $50 / F$ & Left & $\begin{array}{l}\text { Diffuse anterior } \\
\text { scleritis with } \\
\text { fibrinous } \\
\text { anterior uveitis }\end{array}$ & $\begin{array}{l}\text { Yes/ Topical and } \\
\text { oral } \\
\text { (Prednisolone } 1 \% \\
\text { and } 1 \mathrm{mg} / \mathrm{kg} \text { ) }\end{array}$ & Nil & Circumferential & Nil & $\begin{array}{l}\text { Intravenous } \\
\text { third } \\
\text { generation } \\
\text { cephalosporin } \\
\text { with fortified } \\
\text { topical } \\
\text { vancomycin } \\
\text { and } \\
\text { tobramycin }\end{array}$ & $\begin{array}{l}\text { Acute/ chronic } \\
\text { necrotising } \\
\text { scleritis }\end{array}$ \\
\hline 5 & $50 / \mathrm{M}$ & Left & $\begin{array}{l}\text { Nodular } \\
\text { episcleritis }\end{array}$ & $\begin{array}{l}\text { Yes/ Topical and } \\
\text { oral } \\
\text { (Prednisolone } 1 \% \\
\text { and } 1 \mathrm{mg} / \mathrm{kg} \text { ) }\end{array}$ & $\mathrm{Nil}$ & $\begin{array}{l}\text { Quadrant } \\
\left(180^{\circ} \text { temporal, }\right. \\
\text { multiple } \\
\text { settings })\end{array}$ & Nil & $\begin{array}{l}\text { Intravenous } \\
\text { third } \\
\text { generation } \\
\text { cephalosporin } \\
\text { with fortified } \\
\text { topical } \\
\text { vancomycin } \\
\text { and } \\
\text { tobramycin }\end{array}$ & $\begin{array}{l}\text { Acute } \\
\text { necrotising } \\
\text { scleritis }\end{array}$ \\
\hline
\end{tabular}

\section{Figures}




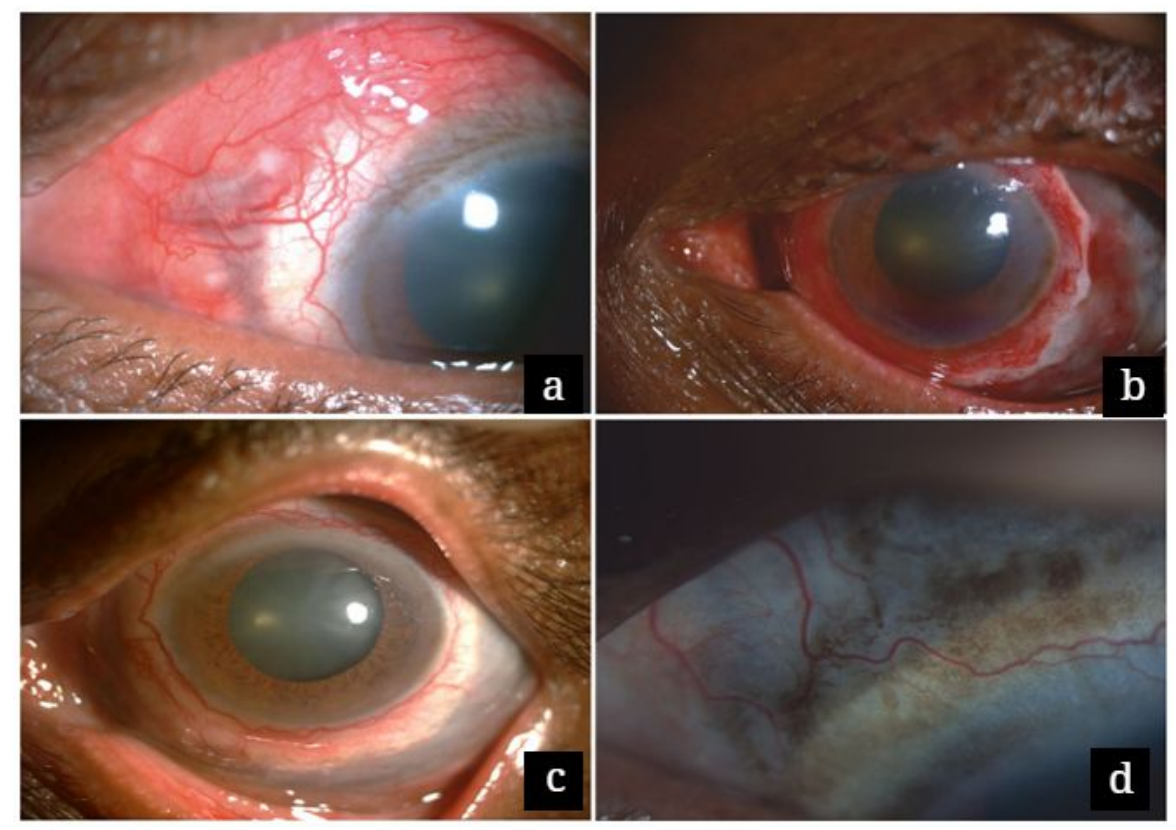

Figure 1

Case 1: (a) Clinical picture prior to debridement shows diffuse scleral involvement (b) Post-operative day-one, showing the bare uveal tissue (c-d) Bare uveal tissue is well epithelised with good anatomical integrity one- month post debridement

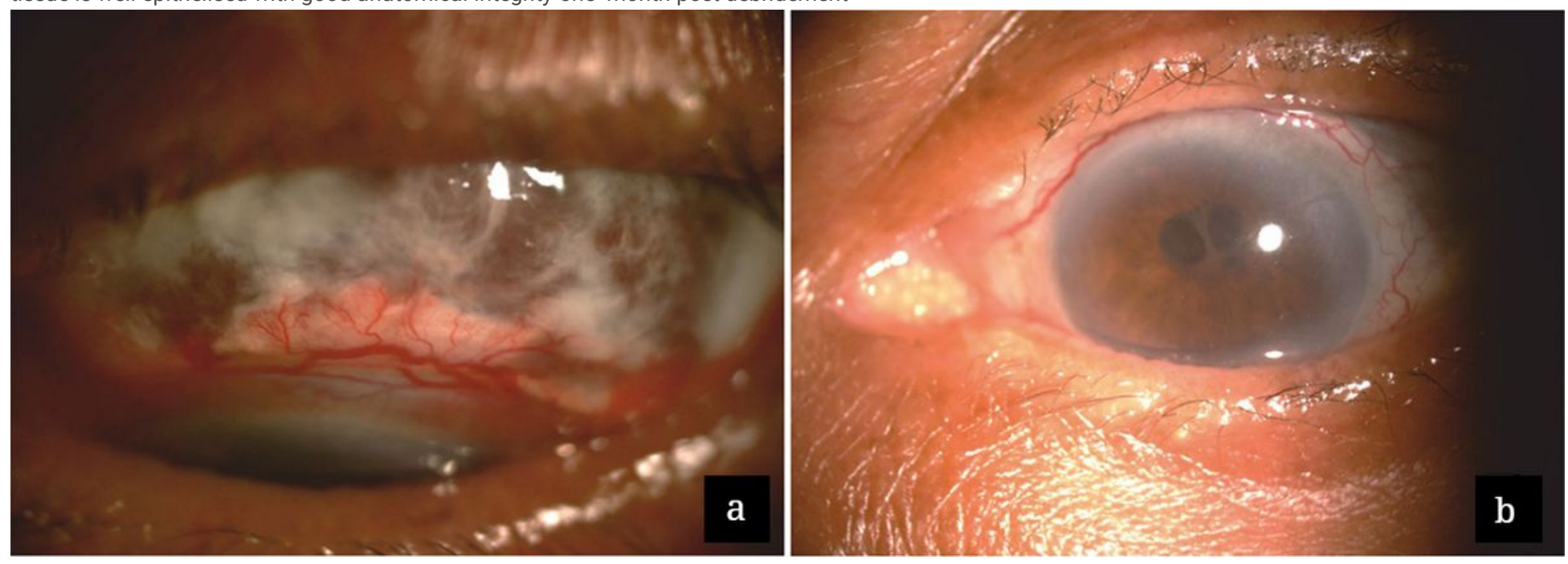

\section{Figure 2}

Case 2: (a) Post debridement day 1 reveals the bare choroidal tissue (b) Epithelisation is complete over the bare choroid one-year post debridement 


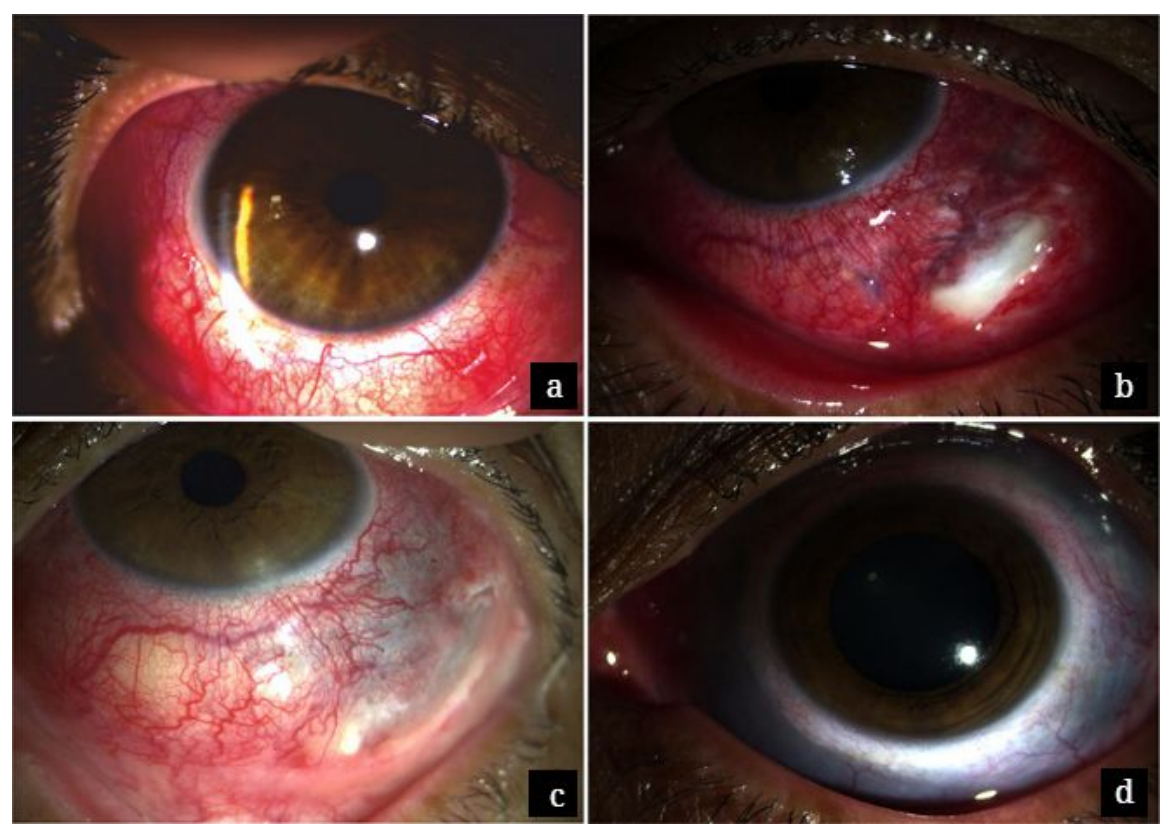

\section{Figure 3}

Case 3: (a) Diffuse scleral involvement (b) Development of scleral abscess after steroid initiation (c) Persistence of scleritis despite localized scleral debridement (d) One year post circumferential debridement, patient shows no signs of recurrence and a normal anatomical contour

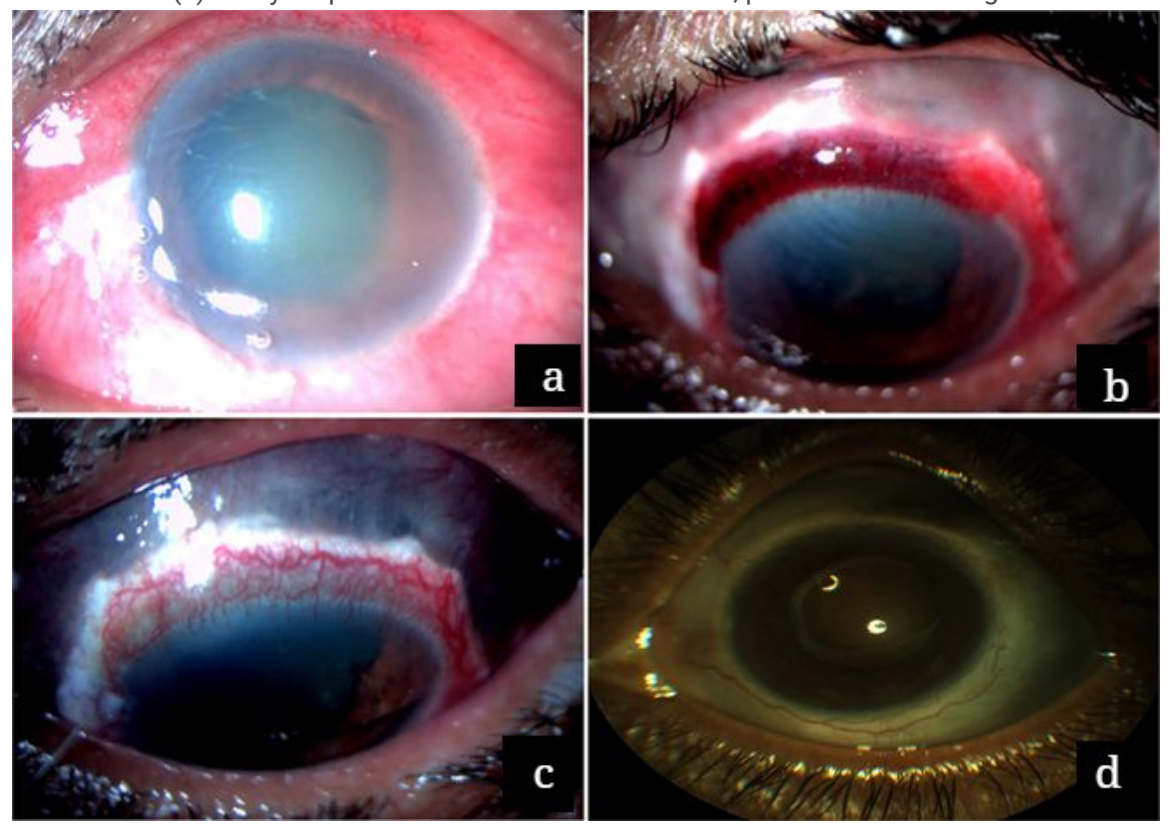

\section{Figure 4}

Case 4: (a) Diffuse scleritis at presentation with anterior chamber reaction (b) Day one after debridement showing the bare choroid (c) Partial epithelisation over the choroid is seen one-month post debridement (d) Quiet eye with no signs of recurrence one-year after debridement and four months following phacoemulsification 


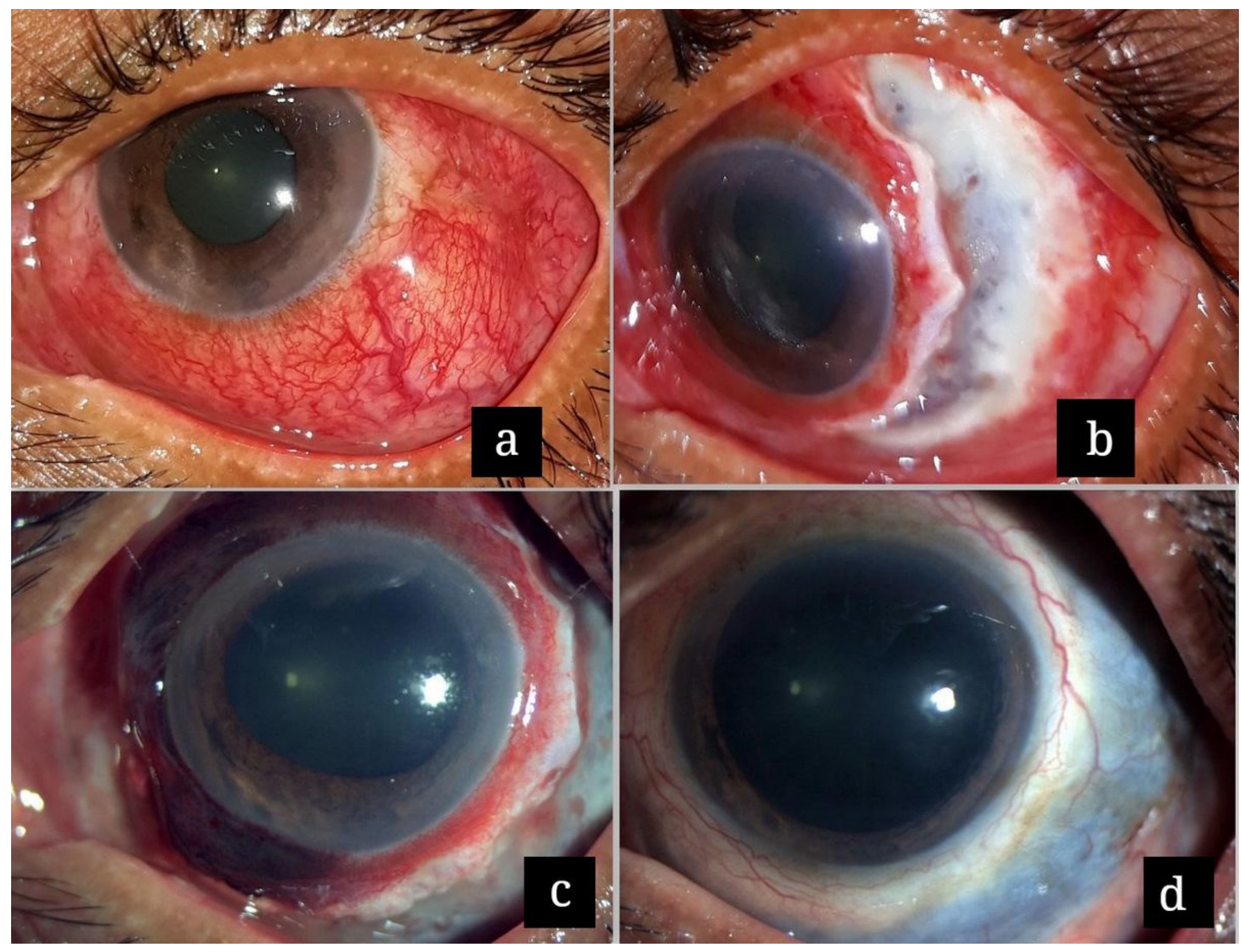

\section{Figure 5}

Case 5: (a) Raised lesion in lower temporal quadrant with tortuous congested vessels (b) Full thickness temporal scleral debridement exposing bare choroid (c) Additional nasal debridement due to progression of scleritis (d) Complete healing and epithelisation with uveal show 